\title{
Socio-cultural acceptability of cadaver Transplantation in Iran
}

\author{
Mobasser $\mathrm{N}^{1}$, Zahmatkeshan $\mathrm{N}^{1}$, Farhadi $\mathrm{N}^{1 *}$, Nikeghbalian $\mathrm{S}^{2}$ and Hasankhani $\mathrm{H}^{3}$ \\ ${ }^{I}$ Department of Operating Room, Yasouj University of medical sciences, Yasouj, Iran; ${ }^{2}$ Department of Surgery, \\ Shiraz University of Medical Sciences, Transplantation Research Centre, Shiraz, Iran; ${ }^{3}$ Department of Nursing, \\ Tabriz University of Medical Sciences, Tabriz, Iran
}

[Received: July 7, Accepted: September 8, 2012]

\begin{abstract}
Organ transplantation is known to be a new and innovative treatment for patients with progressive organ failures. The present study investigates the current status of transplantation from cadaver along with its socio-cultural acceptability in Iran. The present study is a descriptive research in a systematic review method. Here, by investigating previously conducted researches in Iran during the period $2002-$ 2010, the status of transplantation from cadaver and its socio-cultural acceptability in Iran has been investigated. To collect the data, the access to Iranmedex website, the premier medical data center in Iran, was made possible using the related keywords. The obtained data indicate whereas there is an increase in the number of organ donations from cadaver, it is still low in comparison to other countries. The lack of consent from families of brain-dead patients is a major hurdle on the way of organ transplantation in Iran. In the cases of willingness to donate organs, the major effective factors were the deceased's religious beliefs and prior tendency. In $66 \%$ of the cases, the donors' families deemed organ donation phenomenon effective in alleviating the sorrow after the death of their beloved ones. The number of organ donation from cadaver in Iran is low contrary to other countries. It seems that general instructions to raise the knowledge on the subject and lay the foundation to increase the tendency towards posthumous organ donation are necessary.
\end{abstract}

Keywords: transplantation, cadaver, organ donation, Iran

\section{INTRODUCTION}

Organ transplantation has been known as a newly emerged treatment for patients with serious organ failure. It is currently, and at times, the only treatment for many serious diseases ${ }^{[1]}$. Since the purpose by organ transplantation is to cure effectively of diseases in the long run, medical science has paid special attention to organ transplantation in recent years, so that it has improved the frightening perspective of patients facing amputation in their last moments ${ }^{[2]}$. Organ transplantation has managed to improve the patients' quality of life and their vision for the future ${ }^{[3,4]}$. A successful transplantation not only increases the life expectancy and quality, but also proves effective in reducing health expenses ${ }^{[5]}$. Thus, the demand for such a treatment and the number of patients in need of transplantation has increased $70 \%$ more than the past ${ }^{[6]}$. According to a report by The Journal of Medical Services and Resources, there are around 18000, 1800, and 200 individuals waiting to receive kidney, heart and lung respectively at a given day ${ }^{[7]}$.

In United States, annually 20000 peoples suffering from because of trauma but only $15 \%$ of them donate their organs. In other hand, 34000 kidneys, 17000 hearts, lungs, livers and pancreases are destroyed ${ }^{[8]}$. Statistical studies have shown that the difference between the people number in the waiting list and available organs is increasing ${ }^{[9]}$. Depending on the type of the disease, 10 to $25 \%$ of the patients in need on the waiting list die without receiving the organ. ${ }^{1}$
According to a report by Iran's Ministry of Health, more than 15000 brain deaths occur annually as a result of accidents while less than $10 \%$ of them are included as organ donors ${ }^{[10]}$.

Based on the statistics provided by the official website of TPM, in 2008, the number of individuals donating after brain death in Spain, Italy, Brazil, and Iran were $34.3,21.1,7.2$, and 3 in one million people respectively $^{[11]}$.

In the studies conducted in Iran among general population and medical staff, the views on organ donation are varied. For instance, in a study on citizens of Tehran, 93\% agreed with organ donation, and $88 \%$ were willing to fill out organ donation forms ${ }^{[12]}$. Another study in Ahvaz demonstrated $75 \%$ willingness and tendency to donate organs ${ }^{[13]}$, whereas $68 \%$ of the subjects in Tabriz were unwilling to donate organs or fill out the relevant forms ${ }^{[14]}$.

Although an evaluation of the public opinion illustrates great support for organ donation ${ }^{[15]}$, the families' unwillingness to give consent still remains to be the major obstacle on organ donation ${ }^{[16]}$.

In another study in Kerman (Iran) by Dr. Ghadie Pasha et al, the most important reasons given for the opposition to organ donation were the lack of sufficient facilities to train the doctors involved in the issue, as around half of the subjects were not sufficiently informed on organ donation which 
testified there were no effective measures taken in this regard ${ }^{[17]}$.

\section{MATERIALS AND METHODS}

The current research is a descriptive study as a systematic review. By considering the published articles within the period 2002-2010 in Iran, transplantation from cadaver together with its sociocultural acceptability and factors affecting reception or rejection of organ donation in various regions of Iran have been investigated. To have access to the data, the researchers attempted to collect data by reference to Iranmedex data center, otherwise known as the premier source of information on medical sciences publications (visited on the web at www.iranmedex.com). To search in the website, key words such as "brain death", "transplantation from cadaver", "organ donation", and "organ transplantation acceptability" were used. The obtained articles were carefully considered as the sources of information for the researchers, and the current findings derived.

\section{RESULTS}

According to the results, 545 articles on organ donation in Iran were obtained, 35 of which being related to transplantation from cadaver. The findings of the research indicate that the number of organ donations in Iran has been significantly increased from 2002 to 2010 (Figure 1). The results showed that despite a large number of brain deaths caused by accidents in Iran less than $15 \%$ of them were among donors, with more than two third of the families of the brain dead patients unwilling to donate their patients' organs. Further, the collected data indicate that despite having a positive attitude towards the organ donation phenomenon among various groups, individuals' performance is not positive in all instances. In such cases, the findings have considered the positive effect of education in raising public awareness on organ donation.

Religious belief and prior consent are found to be major decision factors for donation. The family members of donors considered donation phenomenon effective in alleviating the sorrow following the death.

\section{DISCUSSION}

In general, one of the major obstacles on organ donation in Iran is the unwillingness of the family and closed relatives of the brain dead patient. According to the studies, around 2.3 Iranian families refuse to donate organs of their close relatives. The level of dissatisfaction among families of the brain dead patients differs from country to country. It has been less than $20 \%$ in some countries like Hungary, Ireland, Poland, Spain, Cuba, and Norway; between $20-50 \%$ in Bulgaria, Estonia, Greece, Italy, Lithuania, Romania, Argentina, Uruguay, and Brazil; and more than $50 \%$ in Panama and Turkey ${ }^{[18,19]}$. Moreover, it has been reported $52 \%$ in US and $60 \%$ in England [20,21]. Also according to the statistical studies in 1995, the number of transplantations were about 20 thousands whereas 8 thousands in Asian countries ${ }^{[17]}$.

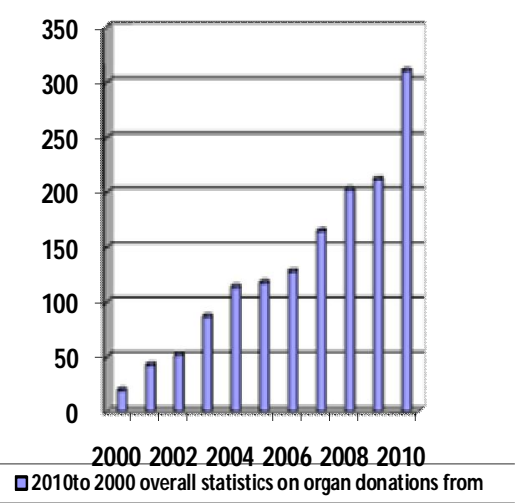

Figure 1: Numbers of organ donation in Iran from 2000 to 2010

Lack of funding, responsibility of politicians, bureaucracy and necessary legislation, shortage of professional organizations responsible for the various religious and lack of public acceptance of organ donation after brain death were crucial reasons in Asian countries ${ }^{[22,23]}$.

Studies conducted in Iran consider factors such as religious beliefs, confidence in the group treatment, care, contradiction, doubt, the deceased beliefs, pain and disability to be effective in family's decision making on approval or disapproval of donating organs of the brain-dead patients. Meanwhile, being aware of the deceased's religious beliefs and ideas had the highest positive effect by easing the decision making of the families. Religious beliefs had been pointed as the major factor affecting this issue ${ }^{[24]}$. It seems that religious beliefs as well as faith in the afterlife among Muslims are important determining factors in convincing the families to decide prudently in that matter. Also according to Rossen et al, when family members know about the deceased's decision to donate organs, it is easy for them to decide to pursue the deceased's wishes and consent to the donation of organs ${ }^{[25]}$. As to the deterrent factors, of the major issues reported are dissatisfaction with and lack of confidence in the medical system and group treatment. Non-donor families were dissatisfied with the medical staff's style of notification regarding the brain dead patients' condition as they believed in their survival. These findings confirm to those by Broogs et al and Klern ${ }^{[26,27]}$. Further, the interval between the donation request and announcement of the brain death, preferably after calling the time of death, is more effective on the tendency to donate ${ }^{[24]}$. Notification by nurses brings about a number of brain dead donors, requiring appropriate awareness of the transplantation. Nurses are the first people 
who observe and report the critical symptoms of brain death to the doctors ${ }^{[7,26,27]}$. As regards the deterrent factors, the findings of Broogs et al demonstrated that making decisions in isolation causes individuals to experience less convenience and confidence in their decisions ${ }^{[26]}$. In a study by Alexi et al when a donation coordinator made the request, more positive responses were reported. In justification of the subject, he states that staffs of organ provider organizations (donation coordinators) are more committed and accountable in dealing with the families and have a more comprehensive knowledge on brain death ${ }^{[28]}$. Findings of another study by Rodrigo et al indicate that when the deceased's prior tendency to donate is not obvious; decision-making is affected by other variables usually with the result of refusal in numerous instances ${ }^{[29]}$. The findings indicate that although organ donation carries no effect on the depression of the family members, donor families find it effective in alleviating the sorrow of losing a beloved one which confirms to the findings of Pearson et al ${ }^{[30]}$. In a study in England in 1985 through a comprehensive educational program on raising the public awareness on brain death and organ donation phenomenon, there had been success in raising the number of donors by $16 \%$ following the instances of brain death from 1986 to $1988^{[29,31]}$.

Our findings indicate that the role of transplantation coordinators in encouraging the families of the brain dead patients to donate is of utmost significance. To this aim, their role would be highlighted by increasing the notification and raising the awareness in the society on the success of transplantations and the humanistic view of Islam towards organ donation.

\section{REFERENCES}

1. Sánchez J, Fischer-Frölich CL (2001). Donor Selection. In: Manyalich M, Cabrer C, ed. Transplant Coordination Manual. Barcelona, TPM Les Heures: Universitat de Barcelona: 6381.

2. Shimazaki J, Shinozaki N, Shimmura S, Holland EJ( 2004). Efficacy and safety of international donor sharing. Transplantation J. 78(2):216-20.

3. Potts, JT (1997). Non-Heart-Beating Donors: medical and Ethical Issues Procurement. Washington, DC: National Academy Press.

4. Schimer J, Roza Bde A (2008). Family, patient and organ and tissue donation: who decides? Transplantation Proc. 40(4):1037-40

5. Najafizade K, Ghorbani F, Bahadory F( 2008). Brain death detection to donation. Tehran: Kian Rayane Sabz Publication; [Persion]

6. RODAT [Homepage the internet](2008). Tehran: International Registry of Organ Donaton and Transplantation; [cited 2009, Dec 27]. Available from: www.tpm.org.
7. United Network for organ sharing (1991). National Patient Waiting list: Report to health resources and services Adm Richmond VA, PHR. 7: 155

8. Delmonico FL, Burdick JF (2006). Maximizing the success of transplantation with kidney from older donors. N Engl J Med. 354(4):411-3.

9. Miranda B, Matesanz R (1998).International issues in transplantation. Setting the scene and flagging the most urgent and controversial issues. Ann NY Acad Sci. 30(862):129-43.

10.Zohoor AR, Piri Z (2004). Attitude of physicians and nurses of Intensive Care Unit to organ transplantation with brain death in the hospitals affiliation with Iran University of Medical Science(TEHRAN-2003). Razi Journal of medical sciences. 11(39): 97-105.

11. Khoddami vishteh HR, Ghorbani F, Ghobadi O, Shafaghi Sh , Barbati ME, Rostami louyeh A, Najafizadeh K (2010). Causes and follow up outcomes of brain dead patients in shahid Beheshti university of medical sciences hospitals . Pejouhandeh. 15(4):171-8.

12. Zohoor AR, Bozorg Magham M (2003). Attitude of Tehran citizens about organ transplantation and donation in brain death. Oroumiyah Medical Journal. 14(1):52-58.

13. Shahbazian H, Dibaei A, Barfi M (2006). Public attitude toward cadaveric organ donation: a survey in Ahwaz. Urol J. 3(4):234-9.

14. Vahidi R GH, Jabbari Bayrami H, Mohammadzadeh Esmaeili H (2003). Beliefs of health staff Tabriz about organ donation. Tabriz Medical Journal. 57:82-84.

15. Siminoff LA, Gordon N, HewlettJ, Arnold RM (2001). Factors Influencing Families' Consent for Donation of Solid Organs for Transplantation. JAMA. 286(1):71-77.

16. West R, Burr G (2002). Why families deny consent to organ donation? Aust Crit Care. 15(1):27-32.

17. Shih FJ, Lai MK, Lin MH, et al (2001). The dilemma of "to-be or not-to-be": needs and expectations of the Taiwanese cadaveric organ donor families during the pre-donation transition. Social Science \& Medicine. 53 (6):693-706

18. Medina-Pestana JO, Sampaio EM, Santos TH, et al (2007). Deceased organ donation in Brazil: how can we improved? Transplantation Proc. 39(2):401-2.

19. International Figures On Organ Donation And Transplantation- 2007. [cited 2010 Feb 1]; Available at: www.ont.es/publications/Documents/Newsletter2 008.pdf

20. Ojo AO, Heinrichs D, Emond JC, et al (2004) Organ donation and utilization in the united states. Am j Transplantation. 4 supple (9):27-37. 
21. Transplant activity of UK, 2007-2008. [cited 2010 Feb 1]; Available at: www.uktransplantation.org.uk.

22. Shrivastava A, Bhandari M, Kumar A, Singh P, Sharma RK (1998). Strategies for increasing transplantation in India and prospects of organ sharing. Transplantation Proc. 30(7):3648.

23. Ota k (1998). Strategies for increasing transplantation in Asia and prospects of organ sharing: Japanese experience. Transplantation Proc. 30(7):3650-2

24. Ahmadian SH, Haghdoost AA, Mohammadalizade S (2008). Effective Factors on the Decision of Families to donate the organ of their Brain dead Relatives. Kerman Medical Science Journal. 16(4):353-363.

25. Rassin M, Lowenthal M, Silner D (2005). Fear, ambivalence, and liminality: key concepts in refusal to donate an organ after brain death. JONAS Healthc Law Ethics Regul. 7(3):79-83.

26. Lewis A, Snell M (1986). Increasing Kidney transplantation in Britania: the importance of donor cards, public opinion and medical practice. Soc Sci Med. 22(10):1075-80.

27. Cleiren M, Van Zoelen AJ (2002). Post-mortem organ donation and grief: A study of consent, refusal and well-being in bereavement. Death Study. 26(10): 837-849.

28. Exley M, White N, Martin JH (2002). Why families say no to organ donation. Crit Care Nurse. 22(6):44-51

29. Rodrigue JR, cornell DL, Howard RJ (2006). Organ Donation Decision: Comparison of Donor and Nondonor Families . Am J Transplant. 6(1): 190-198.

30. Pearson IY, Bazeley P, Spencer-Plane T, Chapman JR, Robertson P (1995). A survey of brain death patients: Their experiences, attitudes to organ donation and transplantation. Anaesth Intensive Care. 23(1):88-95.

31. Zink, S. Wertlieb, S (2006). A study of the presumptive approach to consent for organ donation: a new solution to an old problem. Crit Care Nurse. 26(2):129-36. 